\title{
Modeling the Nd isotopic composition in the North Atlantic basin using an eddy-permitting model
}

\author{
T. Arsouze ${ }^{1,2,3, *}$, A. M. Treguier ${ }^{1}$, S. Peronne ${ }^{1, * *}$, J.-C. Dutay ${ }^{2}$, F. Lacan ${ }^{3}$, and C. Jeandel ${ }^{2}$ \\ ${ }^{1}$ Laboratoire Physique des Océans (LPO), IFREMER/CNRS/UBO/IRD, UMR6523, Plouzané, France \\ ${ }^{2}$ Laboratoire des Sciences du Climat et de l'Environnement (LSCE), CEA/CNRS/UVSQ/IPSL, Gif sur Yvette cedex, France \\ ${ }^{3}$ Laboratoire d'Etudes en Géophysique et Océanographie Spatiale (LEGOS), CNES/CNRS/UPS/OMP/IRD, Toulouse, France \\ *now at: Lamont-Doherty Earth Observatory, Columbia University, Palisades, NY, USA \\ ** now at: Laboratoire de Morphodynamique Continentale et Cotière, UCB-N/CNRS/UR, Caen, France
}

Received: 12 April 2010 - Published in Ocean Sci. Discuss.: 5 May 2010

Revised: 26 July 2010 - Accepted: 20 August 2010 - Published: 1 September 2010

\begin{abstract}
Boundary Exchange (BE - exchange of elements between continental margins and the open ocean) has been emphasized as a key process in the oceanic cycle of neodymium (Nd) (Lacan and Jeandel, 2005a). Here, we use a regional eddy-permitting resolution Ocean General Circulation Model $\left(1 / 4^{\circ}\right)$ of the North Atlantic basin to simulate the distribution of the $\mathrm{Nd}$ isotopic composition, considering BE as the only source. Results show good agreement with the data, confirming previous results obtained using the same parameterization of the source in a coarse resolution global model (Arsouze et al., 2007), and therefore the major control played by the BE processes in the $\mathrm{Nd}$ cycle on the regional scale. We quantified the exchange rate of the $\mathrm{BE}$, and found that the time needed for the continental margins to significantly imprint the chemical composition of the surrounding seawater (further referred as characteristic exchange time) is of the order of 0.2 years. However, the timescale of the BE may be subject to large variations as a very short exchange time (a few days) is needed to reproduce the highly negative values of surface waters in the Labrador Sea, whereas a longer one (up to 0.5 years) is required to simulate the radiogenic influence of basaltic margins and distinguish the negative isotopic signatures of North Atlantic Deep Water from the more radiogenic southern origin water masses. This likely represents geographical variations in erosion fluxes and the subsequent particle load onto the continental margins. Although the parameterization of the BE is the same in both configurations of the model, the characteristic exchange time in the eddy-permitting configuration is significantly lower than the previous evaluations using a low
\end{abstract}

\section{Correspondence to: T. Arsouze} (arsouze@1deo.columbia.edu) resolution configuration (6 months to 10 years), but however in agreement with the available seawater $\mathrm{Nd}$ isotope data. This results highlights the importance of the model dynamics in simulating the BE process.

\section{Introduction}

The seawater neodymium Isotopic Composition (Nd IC, or $\left.\varepsilon_{\mathrm{Nd}}\right)$ varies in the ocean in close relation to the oceanic circulation. $\varepsilon_{\mathrm{Nd}}$ is the part per 10000 deviation of the observed ${ }^{143} \mathrm{Nd} /{ }^{144} \mathrm{Nd}$ ratio from that of the bulk earth (Jacobsen and Wasserburg, 1980). Relatively negative $\varepsilon_{\mathrm{Nd}}$ values are observed in the North Atlantic Ocean, increasing along the path of the global thermohaline circulation up to more radiogenic values in the North Pacific (Piepgras and Wasserburg, 1980; Lacan and Jeandel, 2005a). Changes in Nd IC observed in the water column are related to vertical distribution of water masses. In the Atlantic ocean, the North Atlantic Deep Water (NADW) is characterized by a relatively homogeneous $\varepsilon_{\mathrm{Nd}}$ value ranging from -13 to -14 , whereas the Antarctic Intermediate Water (AAIW) and Antarctic Bottom Water $(\mathrm{AABW})$ are characterized by more radiogenic endmember isotopic signatures of approximately $-8 \varepsilon_{\mathrm{Nd}}$ prior to any mixing with other Atlantic water masses (Piepgras and Wasserburg, 1987; Jeandel, 1993). $\varepsilon_{\mathrm{Nd}}$ is considered to be a "quasi-conservative" tracer $\left(\varepsilon_{\mathrm{Nd}}\right.$ values are conserved for sites distant from source regions) and is used to tag water masses with distinct isotopic compositions in order to constrain water mass mixing and pathways, and the strength of the global thermohaline circulation in paleoceanography.

$\mathrm{Nd}$ sources to the ocean are lithogenic, and the mean Nd IC of a basin is representative of the surroundings continents

Published by Copernicus Publications on behalf of the European Geosciences Union. 
(Albarede et al., 1997; Jeandel et al., 2007). However, the process leading to the transfer of $\mathrm{Nd}$ from the continents to the ocean is still an open debate. Nevertheless, it is generally admitted that the role of hydrothermal inputs is negligible because Nd, as well as all Rare Earth Elements (REE), are effectively scavenged at hydrothermal sites (Michard et al., 1983). It has also been shown that atmospheric dusts and river discharge alone cannot account for both the distributions of Nd IC and Nd concentration, (Tachikawa et al., 2003; Van de Flierdt et al., 2004; Arsouze et al., 2009). Finally, Lacan and Jeandel (2005a) proposed the Boundary Exchange (BE, exchange of elements between water masses and sediments deposited along continental margins) as an important term in the budget of REE in the ocean.

The identification of $\mathrm{Nd}$ sources in the North Atlantic basin has been particularly challenging. Lacan and Jeandel (2005b) confirmed the need to invoke terrigenous inputs originating from the particulate discharge along the Southern Greenland continental margin (distinguished by a very unradiogenic composition), as well as water-mass mixing, to explain the characteristic unradiogenic signature of the NADW. This conclusion complements results from several other studies that also evidenced the influence of BE as a source to explain changes in isotopic signature of water masses in this basin (Lacan and Jeandel, 2004a, b, c). More recently, Rickli et al. (2009) also confirmed this hypothesis. Therefore, the North Atlantic basin is a relevant region to test the impact of $\mathrm{BE}$ on the $\varepsilon_{\mathrm{Nd}}$ oceanic distribution. The high density of observations available, and the importance of this region to the thermohaline circulation, which is of particular interest to study past variations of global circulation, also make this the ideal region to evaluate the role of $\mathrm{BE}$ on the regional scale.

A first attempt to model global Nd IC distribution using a coarse resolution model $(2 \times 2 \times \cos ($ lat $))$ underlined that $\mathrm{BE}$ was an important process among the sources of $\mathrm{Nd}$ to the ocean (Arsouze et al., 2007). In these simulations, the global $\varepsilon_{\mathrm{Nd}}$ gradient between high $\varepsilon_{\mathrm{Nd}}$ in the Pacific and low $\varepsilon_{\mathrm{d}}$ the Atlantic was reproduced, but discrepancies with data were observed in the North Atlantic Ocean where the simulated $\mathrm{Nd}$ isotopic signature was too radiogenic. Invoking dusts or dissolved river inputs could not help to decrease the modeled Nd signature, since these sources are themselves too radiogenic to explain the observed negative signal (Lacan and Jeandel, 2005b). Other possibilities explaining the offset between the simulated distribution and data in the North Atlantic are an under-estimation of the influence of the BE, particularly with the non radiogenic margins in Greenland and along North Canada, or an incorrect representation of the circulation's dynamics in the region. Indeed, although the use of a coarse resolution model was a good compromise for our first global modeling study, such resolution prevented a good representation of boundary currents, simulated as too slow and too diffusive, in particular in the North West Atlantic.
Other global modeling studies contributed to improve our understanding of the oceanic $\mathrm{Nd}$ cycle. Jones et al. (2008) showed that $\varepsilon_{\mathrm{Nd}}$ distribution in the Atlantic basin could be explained via water mass mixing, hence confirming the quasi-conservative property of the Nd IC tracer. Siddall et al. (2009) emphasized the role of the sinking particles in the water column to reconcile both $\mathrm{Nd}$ concentration and IC distribution, using a reversible scavenging model. However, both studies prescribed surface Nd concentration and IC, therefore not focusing on of the question of the $\mathrm{Nd}$ sources into the ocean, which is a prerequisite for the application of $\varepsilon_{\mathrm{Nd}}$ as a water mass tracer. More recently Arsouze et al. (2009) used a coupled global dynamical/biogeochemical model in order to propose an explicit modeling of both $\mathrm{Nd}$ concentration and IC distribution. These authors confirmed that $\mathrm{BE}$ is the dominant $\mathrm{Nd}$ source to the ocean (more than 95\% of the total input), but also evidenced that river inputs and atmospheric dusts are significantly constraining the surface water $\varepsilon_{\mathrm{Nd}}$ values in some areas.

The present study proposes the first simulation of the distribution of $\varepsilon_{\mathrm{Nd}}$ values using an eddy-permitting model, on a regional scale (the North Atlantic basin). Our aim is to estimate the influence of $\mathrm{BE}$ on a regional scale on $\varepsilon_{\mathrm{Nd}}$ distribution, and to determine the timescale on which this process acts at such regional scales when compared to previous estimates on global scale (Arsouze et al., 2007). It is of particular interest because it may help to indicate what are the processes involved in this exchange. On the one hand, high resolution and good representation of boundary currents at the ocean margins are essential in order to improve simulation of processes occurring at the sediment/water interface and further favor the development of more realistic and sophisticated parameterizations of the BE: this justified the use of an eddy permitting model $1 / 4^{\circ}$. On the other hand, the explicit representation of the tracer sources and sinks proposed in Arsouze et al. (2009) was hardly applicable in this configuration regarding to the induced high computational cost. We therefore adopted a similar approach to that of Arsouze et al. (2007), i.e. considering BE as the only Nd source, parameterized via a relaxation term along the continental margin.

\section{Description of the model and $\varepsilon_{\mathrm{Nd}}$ modeling}

We use the NEMO numerical model (Madec, 2008), in the regional eddy permitting configuration NATL4, extracted from the global $1 / 4^{\circ}$ configuration ORCA025 (The Drakkar Group, 2007; Le Sommer et al., 2009). The domain includes the North Atlantic basin and Nordic Seas, extending from $20^{\circ} \mathrm{S}$ to $80^{\circ} \mathrm{N}$ in latitude, and up to $23^{\circ} \mathrm{E}$ in Mediterranean. Buffer zones are prescribed on the open boundaries of the domain. The vertical resolution (46 levels) ranges from $6 \mathrm{~m}$ in the upper layer, to 250 mat depth. We use partial-steps to adjust the last numerical level with the bathymetry. 
Table 1. Summary of the main characteristics for each experiment.

\begin{tabular}{llccl}
\hline Experience & Relaxing time $\tau$ & $\begin{array}{c}\text { Percentage of points that } \\
\text { reproduce the data with } \\
\mathrm{a} \pm 3 \varepsilon_{\mathrm{Nd}} \text { accuracy. }\end{array}$ & $\begin{array}{c}\text { Percentage of points that } \\
\text { reproduce the data with } \\
\mathrm{a} \pm 1 \varepsilon_{\mathrm{Nd}} \text { accuracy. }\end{array}$ & $\begin{array}{l}\text { Regression coefficient } \\
\text { for data/model points }\end{array}$ \\
\hline EXP1 (NATL4) & 1 day & 57.91 & 25.63 & 1.231 \\
EXP2 (NATL4) & 0.2 year & 75.63 & 33.54 & 0.7227 \\
EXP3 (NATL4) & 0.5 year & 74.68 & 38.92 & 0.5708 \\
EXP4 (NATL4) & 1 year & 73.73 & 38.61 & 0.4553 \\
EXP5 (NATL4) & 0.1 year $\left(\max \varepsilon_{\mathrm{Nd}_{\text {mar }}}\right.$ ) to & 57.91 & 25.95 & 0.5564 \\
& 0.5 year $\left(\min \varepsilon_{\mathrm{Nd}_{\mathrm{mar}}}\right)$ & & 32.28 & 0.6693 \\
ORCA2 & 1 year & 68.04 & 3.04 & \\
\hline
\end{tabular}

The dynamic simulation is integrated for 20 years (1980 to 2000) from a climatological initial condition (Levitus et al., 1998) and using the Drakkar interannual atmospheric forcing DFS3. All $\varepsilon_{\mathrm{Nd}}$ simulations were run "offline", using the passive tracer model (Ethé et al., 2006), using the last 10 years of the pre-calculated dynamical fields (output averaged every 5 days), providing a statistical mean state of the ocean circulation. The tracer is then integrated until equilibrium is reached (i.e. 160 years, cycling 16 times over the dynamical fields).

Comparison of the dynamical features simulated by the model between global coarse and regional eddy-permitting resolution shows large differences. Indeed, the transports are comparable in both configurations but the currents are much more vigorous in the eddy-permitting configuration. Barnier et al. (2006), Penduff et al. (2007) and Le Sommer et al. (2009) show how the use of an energy- and enstrophyconserving momentum advection scheme in NEMO at $1 / 4^{\circ}$ yielded a clear improvement in the simulation of currenteddy-topography interactions, and thus of along-topography circulations. Comparisons between a large current meter database (Holloway, 2008) and two DRAKKAR global ocean simulations (T. Penduff, personal communication, 2009) confirm that increasing NEMO's resolution from $2^{\circ}$ to $1 / 4^{\circ}$ yields a large reduction of local model-observation mismatches, both in terms of mean current strengths (which increase toward observed levels) and directions (aligning with measured flows more nearly along isobaths), in particular along basin margins where many current meters are located.

Arsouze et al. (2007), in the global configuration of the model, defined $\mathrm{BE}$ as a source/sink term, $S\left(\varepsilon_{\mathrm{Nd}}\right)$, in the equation of conservation of the tracer, that is parameterized by a relaxation term between the continental margin and the ocean:

$S\left(\varepsilon_{\mathrm{Nd}}\right)=1 / \tau \times\left(\varepsilon_{\mathrm{Nd}_{\mathrm{mar}}}-\varepsilon_{\mathrm{Nd}}\right) \times$ mask $_{\mathrm{mar}}$

where $\tau$ is the characteristic relaxing time, $\varepsilon_{\mathrm{Nd}_{\mathrm{mar}}}$ is the $\varepsilon_{\mathrm{Nd}}$ value of the material deposited along the continental margin, mask $\mathrm{mar}_{\mathrm{m}}$ is the percentage of surface bathymetry in a numerical grid cell of the model (determined using the $1 \mathrm{~min}$ resolution bathymetry Gebco) and $\varepsilon_{\mathrm{Nd}}$ is the $\mathrm{Nd}$ IC value of the ocean. In the following experiments, we use the same parameterization as Eq. (1), refining the scale of the interpolation of $\varepsilon \mathrm{Nd}_{\operatorname{mar}}$ value compared to the map used on global scale using data compilation by Jeandel et al. (2007), and with mask $_{\text {mar }}$ recalculated on the NATL4 grid. We thus only model Nd IC, and make the implicit hypothesis of a constant $\mathrm{Nd}$ concentration. This hypothesis might seem simplistic, but is however necessary as a first approach of modeling $\varepsilon_{\mathrm{Nd}}$ in an eddy-permitting model, and has already been validated on a global configuration (Arsouze et al., 2007). By definition from Eq. (1), $\tau$ is the timescale of the $\mathrm{BE}$ as defined previously, i.e. the time needed for processes to transfer chemical properties from the continental margin to the overlaying water-mass.

Because this is not a global GCM we have model boundaries in the open ocean in the high North Atlantic and South Atlantic that must be prescribed. We prescribe $\varepsilon_{\mathrm{Nd}}$ values for these "open ocean boundaries" using literature data from Signature 29 and Signature 30 data in the North Atlantic (Lacan and Jeandel, 2004a,c), and SAtl 217, SAtl 271 and SAtl 302 data at the South Atlantic (Jeandel, 1993). Prescribing these open ocean boundary conditions is similar to applying a relaxing term with a short characteristic relaxing time, which tags waters entering the basin with a Nd IC consistent with observations.

Four tests on the characteristic relaxing time are performed: experiments EXP1, EXP2, EXP3 and EXP4 have $\tau=1$ day, 0.2 year (2.4 months), 0.5 year (6 months), and 1 year, respectively (cf. Table 1). In a last experiment (EXP5), we explore the possibility that our BE parameterization might be dependant on the mineralogical maturity of margin sediments (e.g. granitic vs. basaltic). We tested this by scaling the characteristic exchange time $(\tau)$ to the $\mathrm{Nd}$ IC of the margin $\left(\varepsilon_{\mathrm{Nd}_{\mathrm{mar}}}\right)$, so that exchange occurs faster along basaltic margins. We included this test because basaltic sediments contain minerals that are unstable at the Earth's surface and thus erode much faster than granitic sediments 

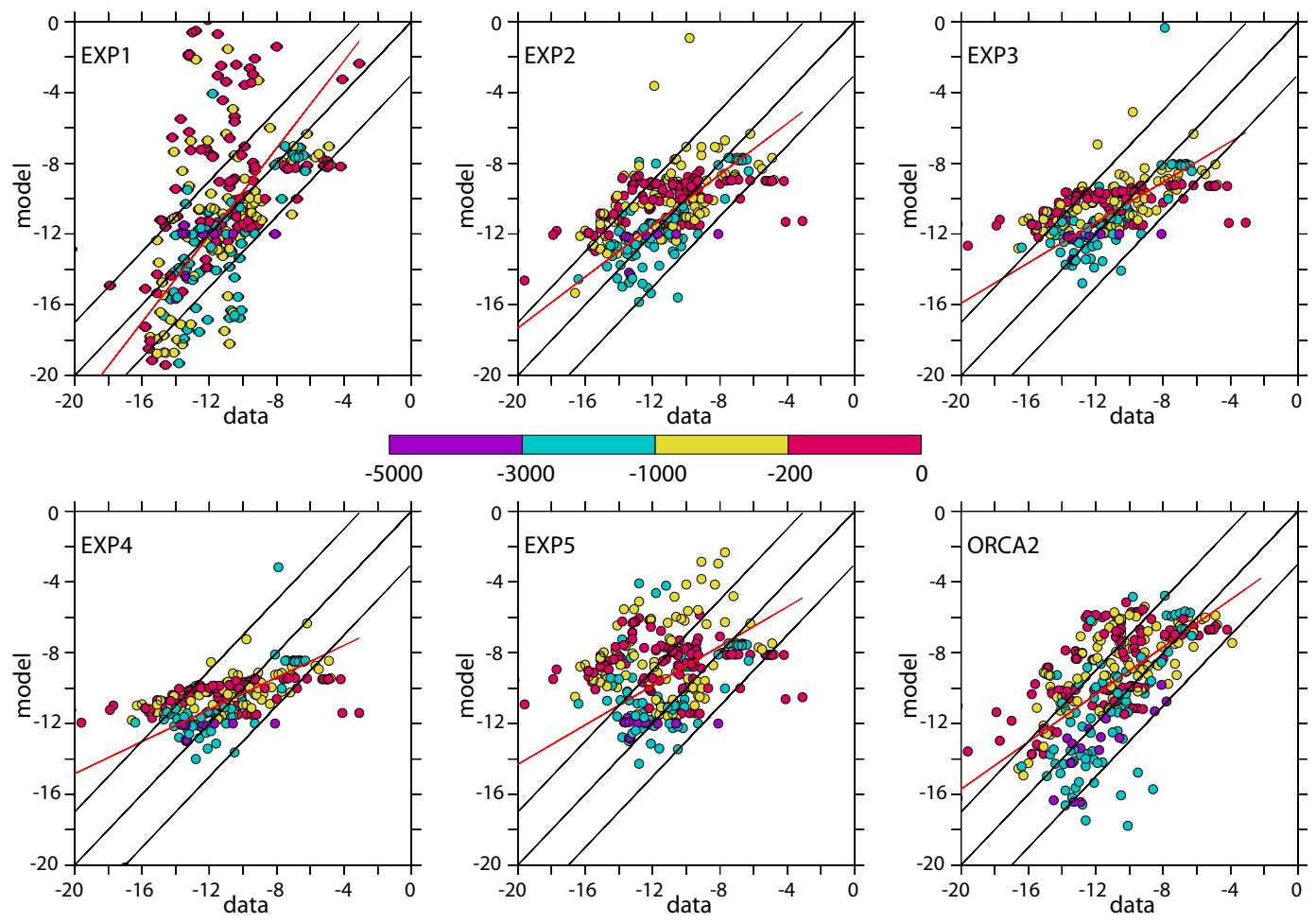

Fig. 1. Model/data comparison as a function of depth (color code) for the 5 simulations performed with the model in NATL4 configuration. The extraction in the North Atlantic from a previous simulation using the global ORCA2 configuration, with a relaxing time of 1 year, is also shown. Red line is the linear regression of the points. Diagonal black lines are lines $\varepsilon_{\mathrm{Nd}}\left(\right.$ modeled) $=\varepsilon_{\mathrm{Nd}}($ data $), \varepsilon_{\mathrm{Nd}}(\mathrm{modeled})=\varepsilon_{\mathrm{Nd}}$ (data) $+3 \varepsilon_{\mathrm{Nd}}$ and $\varepsilon_{\mathrm{Nd}}$ (modeled) $=\varepsilon_{\mathrm{Nd}}$ (data) $-3 \varepsilon_{\mathrm{Nd}}$. In EXP5, relaxing time varies from $\tau=0.1$ years for margins associated with a "high $\varepsilon_{\mathrm{Nd}}$ " value $(=+8)$, to a relaxing time of $\tau=0.5$ years for margins associated with a "low $\varepsilon_{\mathrm{Nd}}$ " value $(=-38)$. A linear relationship is set between those two extrema values. Main statistical characteristics for each experiment are reported in Table 1.

(Amiotte Suchet et al., 2003; Dessert et al., 2003). Hence, $\tau$ is set to vary linearly from 0.1 years for the most radiogenic Nd IC values $\left(\varepsilon_{\mathrm{Nd}_{\text {mar }}}=+8\right.$ along the Iceland margin) to 0.5 years for the most non-radiogenic values $\left(\varepsilon_{\mathrm{Nd}_{\mathrm{mar}}}=-38\right.$ on the South-East Greenland). This parameterization might be too simplistic, but the current knowledge of the processes involved in sediments' dissolution does not allow for a more sophisticated implementation. Finally, for comparison purpose with the present sensitivity tests, we present an extraction of the North Atlantic basin from a previous simulation (Arsouze et al., 2007) in the ORCA2 $\left(2^{\circ} \times 2^{\circ} \cos (\right.$ lat $\left.)\right)$ configuration with a relaxing time of 1 year.

\section{Results}

The simulated $\varepsilon_{\mathrm{Nd}}$ distributions are in good agreement with the data (Figs. 1, 2, 3 and 4, Table 1), though BE is considered as the only source of Nd to the ocean. More specifically experiments EXP2 and EXP3 (relaxing time of 0.2 years and 0.5 years respectively) simulate in both cases $76 \%$ of the observed $\varepsilon_{\mathrm{Nd}}$ values with \pm 3 unit accuracy (and almost $40 \%$ with $\pm 1 \varepsilon_{\mathrm{Nd}}$, Fig. 1 and Table 1), with correlation coefficients close to 0.65 , and a standard deviation very close to the data for EXP2 (Fig. 1). The remaining errors affecting the simulated values are mainly corresponding to surface or sub-surface samples located close to radiogenic coastal shelves, in particular along the Greenland - Iceland - Scotland ridge (Fig. 3).

These results are in better agreement than in the previous coarse resolution global modeling (ORCA2), with a relaxing time of 1 year (68\% and $32 \%$ within \pm 3 and \pm 1 units errors respectively, Fig. 1). These simulations generated strong geographical gradients in $\varepsilon_{\mathrm{Nd}}$, particularly in surface waters along the continental margins (leading to patchy effects), suggesting an overestimation of the exchange (Figs. 3 and 4 in Arsouze et al., 2007). Contrastingly, the regional eddypermitting resolution (NATL4) simulation with the same relaxing time (1 year) leads to a homogeneous distribution in surface waters (Fig. 2, EXP4, Table 1). An extremely short relaxing time of 1 day (EXP1) leads to large disparity in simulated $\varepsilon_{\mathrm{Nd}}$ values, including non-realistic radiogenic extremes near Iceland-Scotland and Caribbean Sea. Our first experiment (EXP1) is the only experiment that successfully simulates the observed negative $\varepsilon_{\mathrm{Nd}}$ values in surface waters of Labrador Sea (Fig. 2). 

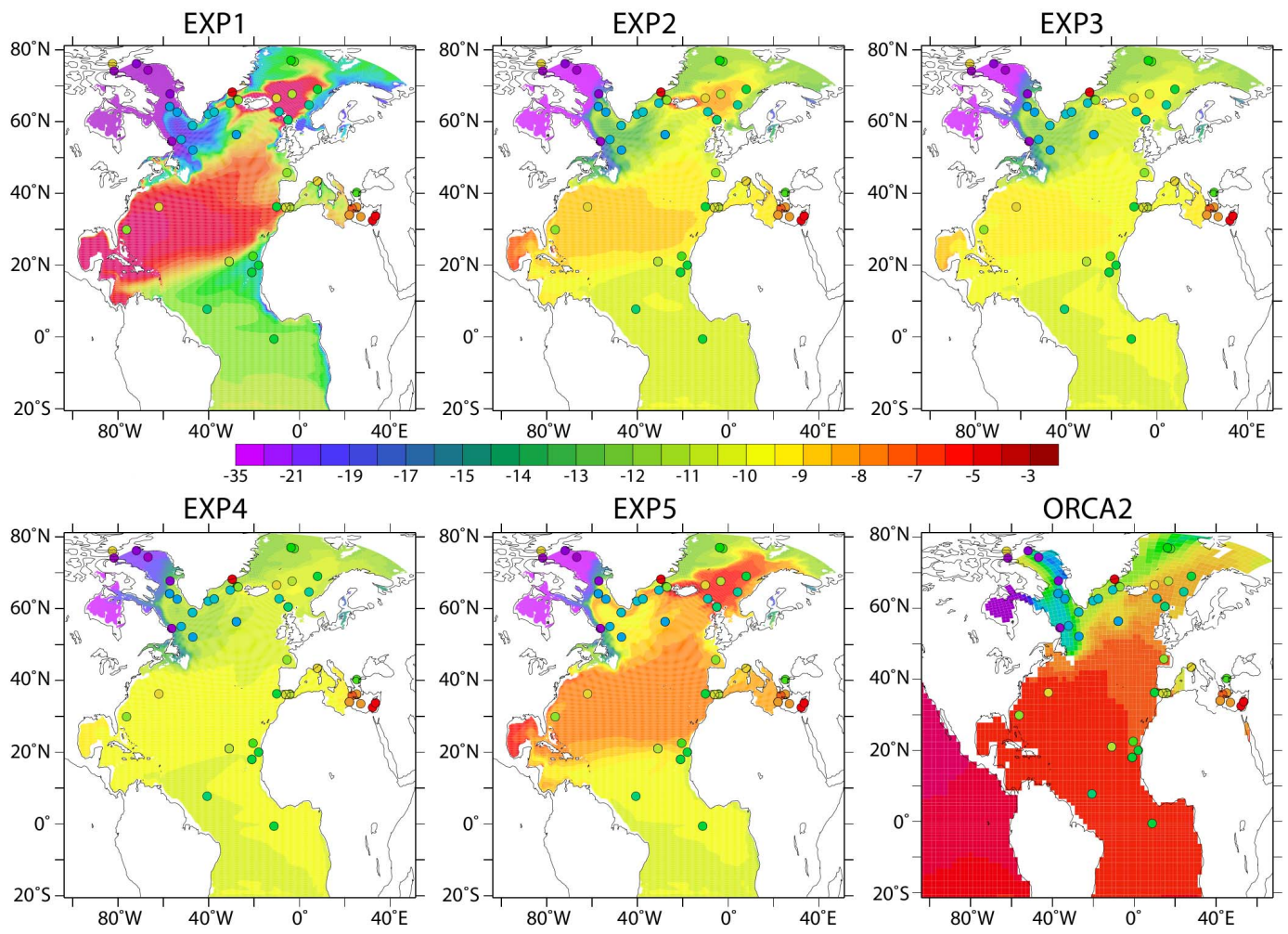

Fig. 2. 100m-depth $\varepsilon_{\mathrm{Nd}}$ distribution map, for the 5 simulations performed using the model in NATL4 configuration. EXP1: A map of the $\varepsilon_{\mathrm{Nd}}$ distribution at the same depth, from a previous simulation using the global ORCA2 configuration, with a relaxing time of 1 year, is also shown. Superimposed circles represent the data between 50 and $300 \mathrm{~m}$ depth. Color scale is the same for both simulation output and data, and is nonlinear. Data are issued from Piepgras and Wasserburg (1980, 1983, 1987), Stordal and Wasserburg (1986), Spivack and Wasserburg (1988), Tachikawa et al. (1999), Lacan and Jeandel (2004a,b,c, 2005a,b), Dahlqvist and Andersoon (2005) and Rickli et al. (2009) and compiled by F. Lacan and K. Tachikawa (available here: http://www.legos.obs-mip.fr/fr/equipes/geomar/results/database_may06.xls).

At depth (Fig. 4), all simulations EXP2, EXP3 and EXP4 ( $\tau=0.2$ year, 0.5 year and 1 year respectively) display comparable features, in good agreement with the data. In particular these deep results are much closer to the data than those obtained with ORCA2. Experiment $\tau=1$ day (EXP1) generates deep waters that are too negative.

(EXP5) was run assuming that volcanic margins are releasing their $\mathrm{Nd}$ more than the granitic ones, volcanic fields being known to be more easily weathered than granitic ones. This experiment generates seawater $\varepsilon_{\mathrm{Nd}}$ that is globally too radiogenic in the basin, both in surface and at depth (Figs. 1, 2, 3 and 4), particularly along the Caribbean arc and the Iceland-Scotland ridge.

Consistently with the results obtained with the global scale simulations, we find that a long characteristic exchange time induces longer residence time, and finally more homogeneous $\varepsilon_{\mathrm{Nd}}$ values in the basin, at all depths.

\section{Discussion}

The results presented here confirm on a regional scale what has been previously suggested on a global scale: by assuming $\mathrm{BE}$ as the only $\mathrm{Nd}$ oceanic source term, it is possible to reproduce the main features of the distribution of its isotopic composition in the basin. This reinforces the preceding conclusions on $\mathrm{BE}$ as an important process in the $\mathrm{Nd}$ oceanic cycle.

One striking difference between these results and our previous results (Arsouze et al., 2007) is that the ideal characteristic exchange time $\tau$ is much shorter when deduced from eddy-permitting resolution simulations (NATL4) than from coarse resolution ones (ORCA2). The coarse resolution configuration (ORCA2) yielded an ideal exchange time varying from 6 months in surface to 10 years at depth. The most realistic reproduction of $\varepsilon_{\mathrm{Nd}}$ distribution for the eddypermitting model uses a relaxing time of 0.2 or 0.5 years, or even of the order of few days in surface and subsurface to correctly reproduce the highly non-radiogenic waters in the Labrador Sea. This very short relaxing time implies a very intense exchange with the margins of the studied region. The 

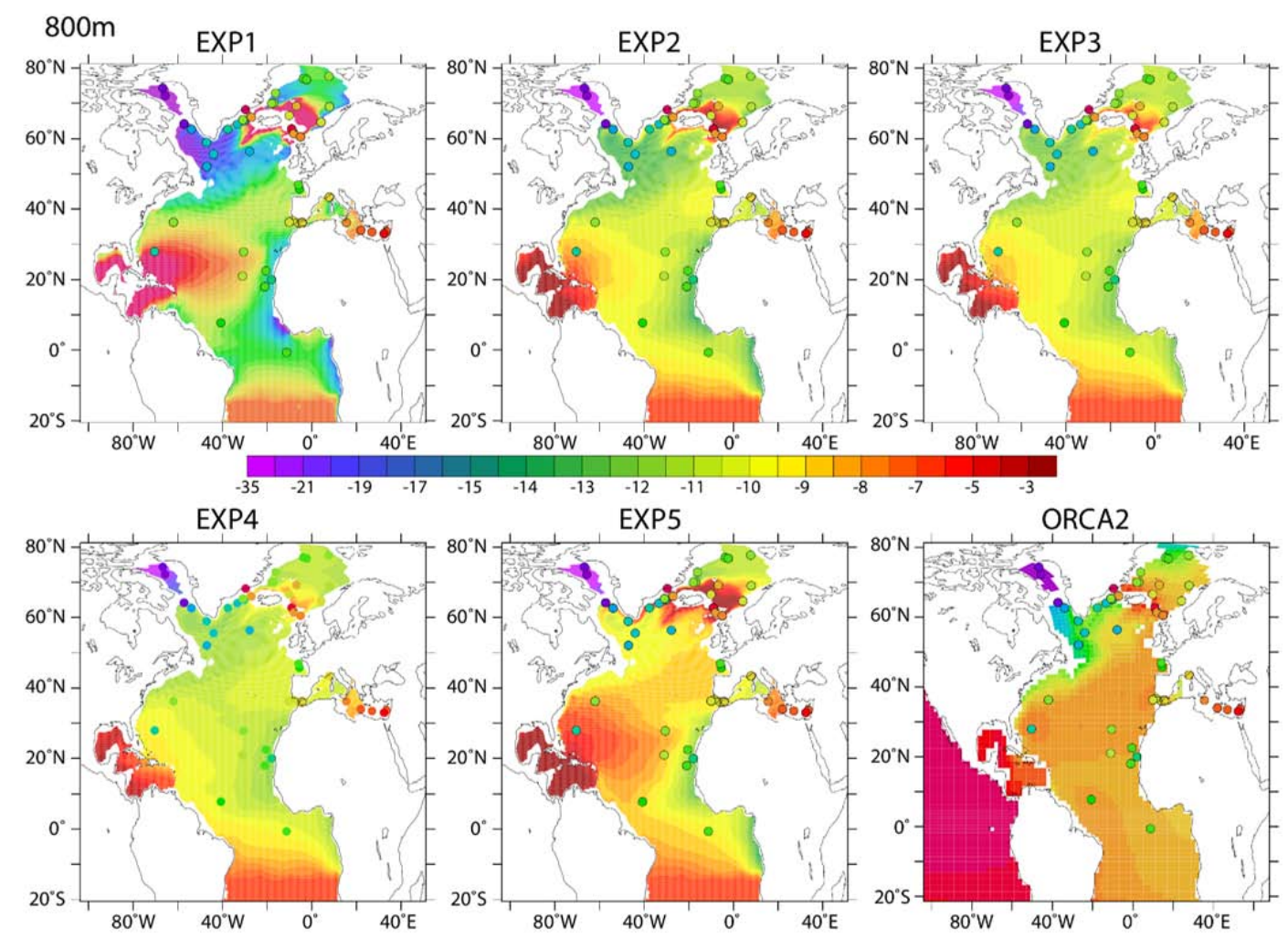

Fig. 3. Same as Fig. 2, but at $800 \mathrm{~m}$ depth. Data plotted (circles) are from 500 to $1000 \mathrm{~m}$ depth. Data are issued from Piepgras and Wasserburg (1980, 1983, 1987), Stordal and Wasserburg (1986), Spivack and Wasserburg (1988), Tachikawa et al. (1999), Lacan and Jeandel (2004a,b,c, 2005a,b), Dahlqvist and Andersoon (2005) and Rickli et al. (2009) and compiled by F. Lacan and K. Tachikawa (available here: http://www.legos.obs-mip.fr/fr/equipes/geomar/results/database_may06.xls).

rapid exchange rates suspected here are consistent with recent $\varepsilon_{\mathrm{Nd}}$ data that suggest an input from continental margins within only few weeks at the Kerguelen Islands, another region where high dynamical forcing is present (Zhang et al., 2008).

Representing explicitly the $\mathrm{Nd}$ source flux in the ocean such as Arsouze et al. (2009) appears as a solution to avoid the strong dependence of the Nd flux parameterization (the relaxing time $\tau$ ), with respect to the model resolution. Indeed, when using Eq. (1) to represent the BE, the $\varepsilon_{\mathrm{Nd}}$ signal of the water-mass in contact with a continental margin is directly recorded and memorized downstream. On the contrary, the explicit representation of $\mathrm{Nd}$ flux coming from the margins is from most part compensated by an important sink (Boundary Scavenging), leading to an almost constant concentration through the BE process, independently of the dynamics of the water mass.

The short relaxing time required to accurately represent $\mathrm{BE}$ could reveal that sources other than BE - and not represented here - are missing. Indeed, even if BE is largely dominating the other sources of $\mathrm{Nd}$ to the whole ocean (about 90\% or more; Tachikawa et al., 2003; Arsouze et al., 2009), Nd IC distribution at the near surface is for the most part reflecting river and aerosols inputs (Piepgrass and Wasserburg, 1987; Arsouze et al., 2009). However, the northern part of the Atlantic is barely affected by these two kinds of sources. Indeed, Lacan and Jeandel (2005b) showed that dissolved river input and atmospheric dusts can rarely account for missing source in the Nordic Seas or in the Labrador Sea because (1) their IC are not compatible with the shift observed along the water-mass path, and/or (2) their total input is much lower than the flux required to reproduce the observed isotopic gradient. For example, these authors estimated that dissolved rivers discharge and atmospheric dust inputs account for only $8 \%$ and $1 \%$ of the observed isotopic signature change along the path of formation of the North West Atlantic Bottom Water (at $2700 \mathrm{~m}$ depth), respectively. However, these last sources might have some local effects in surface-subsurface waters. Though limited, the influence of these sources in the $\varepsilon_{\mathrm{Nd}}$ distribution could lead to the largest discrepancies observed when compared with the data near continents.

This short characteristic exchange time found with the regional modeling likely reflects the reproduction of boundary currents which are more realistic and vigorous in NATL4 than in ORCA2, and includes an explicit representation of 

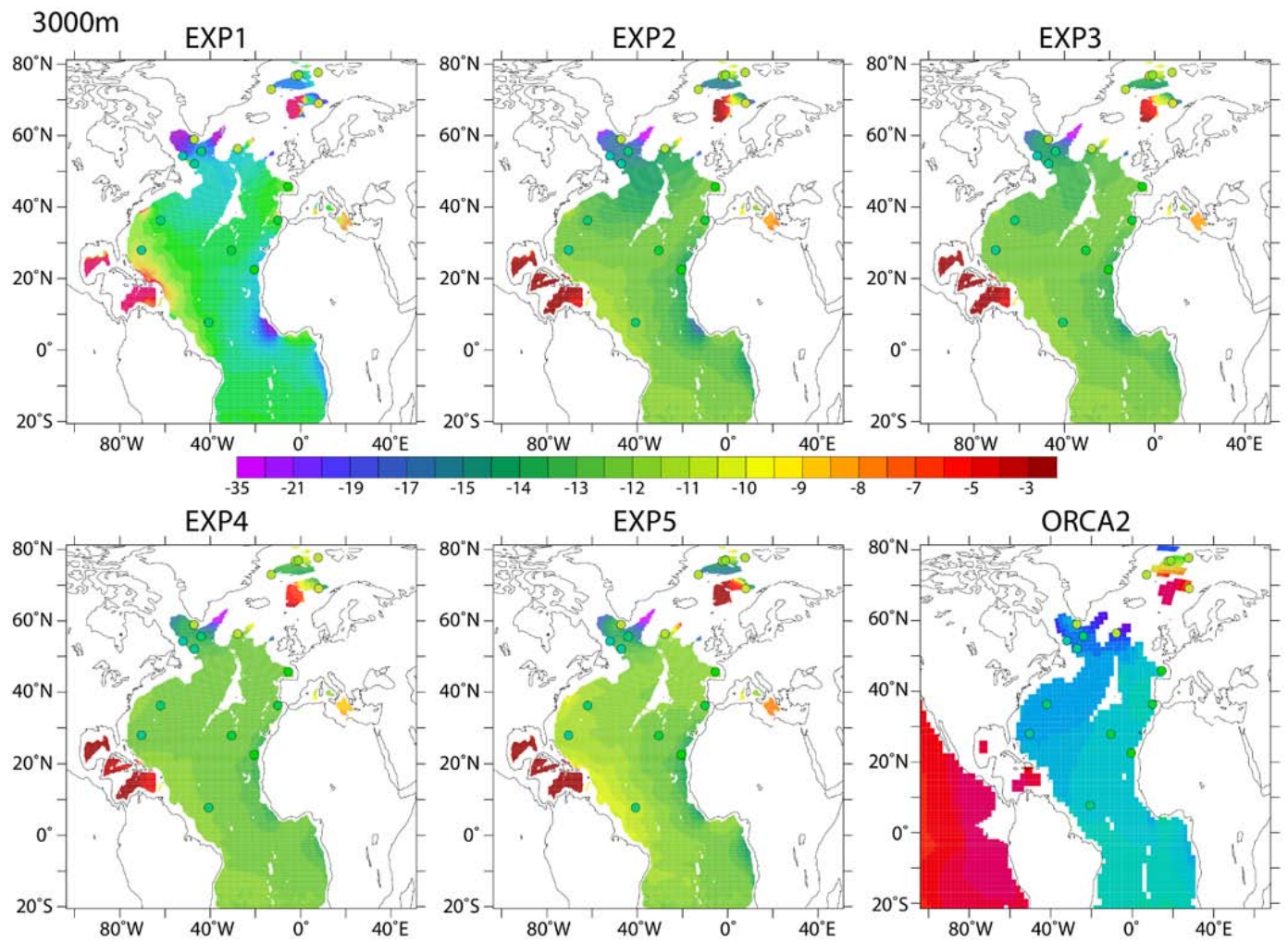

Fig. 4. Same as Fig. 2, but at $3000 \mathrm{~m}$ depth. Data plotted (circles) are from 2500 to $3500 \mathrm{~m}$ depth. Data are issued from Piepgras and Wasserburg (1980, 1983, 1987), Stordal and Wasserburg (1986), Spivack and Wasserburg (1988), Tachikawa et al. (1999), Lacan and Jeandel (2004a,b,c, 2005a,b), Dahlqvist and Andersoon (2005) and Rickli et al. (2009) and compiled by F. Lacan and K. Tachikawa (available here: http://www.legos.obs-mip.fr/fr/equipes/geomar/results/database_may06.xls).

meso-scale processes. Sluggish water masses and important diffusion generated in the ORCA2 configuration (Dutay et al., 2004) overestimate the residence time of water masses in contact with continental margins and thus enhance the local influence of the margin isotopic signature. Thus, simulation with a relaxing time of 1 year in the ORCA2 configuration leads to strong geographical gradients, whereas simulation using the same relaxing time in the NATL4 configuration leads to a nearly homogenized basin. This underscores the importance of Boundary Current representation to simulating the Boundary Exchange and the resulting $\varepsilon_{\mathrm{Nd}}$ distribution. This issue will have to be considered when dealing with future global high-resolution configuration models. Note that although improved relative to ORCA2, boundary currents in NATL4 are not realistic enough yet to warrant a more detailed examination of the $\varepsilon_{\mathrm{Nd}}$ model-data misfit. For example, there is too much entrainment in the modeled Denmark Strait overflow when compared to the data. This alters the dynamics and physical properties of the Lower North Atlantic Deep Water downsteam (this is a familiar flaw in models with geopotential vertical coordinates, e.g., Willebrand et al., 2001), leading to biases in the acquisition of the isotopic signature of the water-mass when in contact with the margin.
EXP5 suggests that in the studied area, the BE process does not seem to be more sensitive to basaltic than to granitic margin sediments. This observation does not assess that margin-to-water inputs of $\mathrm{Fe}$ or $\mathrm{Nd}$ in this area that are suspected to result from lithogenic silicate dissolution (Lacan and Jeandel, 2005a; Moore and Braucher, 2008; Jeandel et al., 2010) are favored by the high solubility of basalts (Dessert et al., 2003). Nevertheless, this last result has to be taken cautiously because the parameterization used between $\mathrm{BE}$ and the margin lithology might be too simplistic, as well as the margin geological characteristics.

Shortcomings are also remaining in EXP2 (best correspondence with data within all sensitivity tests performed in this study, Table 1, Figs. 1 and 2). The main discrepancy resides in the very radiogenic Caribbean Islands that over-imprint the water masses in the southwestern part of the domain, despite the occurrence of un-radiogenic continents surrounding the Caribbean Sea. This was also observed with the global model (ORCA2). However, there is no Nd data in the Caribbean Sea, so that we cannot confirm this result. Further documentation of this area (as planed in the framework of GEOTRACES program for example) would help to better understand the possible BE sensitivity to the lithology 
of the margin sediment, sensitivity suspected to be important based on seawater data from the Greenland - Scotland (Lacan and Jeandel, 2004a,b). Production of non-realistic radiogenic values in this area is likely due to overestimated inputs from this basaltic ridge, reflecting biases in the parameterization of the continental margin and the limitation of the definition of $\mathrm{BE}$ as a simple function of the topography (via the mask $_{\text {mar }}$ term, cf. Eq. 1). In order to reduce these artifacts, and also explain the large geographical variations observed in the value of the characteristic exchange time, it might be useful to couple the BE parameterization to a geographical sediment delivery map that effectively represents the amount of material available on the continental margins to be exchanged with the surroundings water masses. Also taking into account the $\mathrm{Nd}$ concentration variations along the continental margins might help constraining the value and the range of variations of the relaxing time $\tau$.

\section{Conclusions}

In this study, $\varepsilon_{\mathrm{Nd}}$ distribution was simulated using the regional NEMO/NATL4 eddy-permitting model in the North Atlantic Ocean. Boundary Exchange (BE) parameterization was performed via a relaxing term.

The characteristic margin-to-ocean exchange time is reestimated to be between few days and 6 months in the NATL4 configuration, significantly shorter than previous estimations of 6 months to 10 years, estimated from the global low resolution ORCA2. The reduced exchange time and the inclusion of the eddy permitting model yielded results that are in better agreement with the available data, especially largely improving the $\mathrm{Nd}$ isotopic signature of the deepest water masses. This work highlights the dependency of the parameterization of BE to the model and dynamics used. In particular, a better reproduction of Boundary Currents in the NATL4 configuration compared to ORCA2 configuration is a key factor to better estimate the characteristic exchange time of the Boundary Exchange process and to improve the simulation of marine $\mathrm{Nd}$ isotopes. Ongoing work on the reproduction of overflows and on configurations of the model at a higher resolution will produce a more realistic representation of boundary currents, and subsequently help refining the $\mathrm{BE}$ time scale.

However, this important model-dependency does not undermine the importance of the BE hypothesis. Instead, though we cannot rule out the importance of any other source of $\mathrm{Nd}$ in the basin, we found that considering the source of the $\mathrm{BE}$ as the only $\mathrm{Nd}$ oceanic input term leads to a very satisfying Nd IC distribution that closely matches observations in the whole basin. Available data in the region (Lacan, 2002) and global modeling (Arsouze et al., 2009) suggest that sediment remobilization, rather than hydrothermal inputs, atmospheric dusts or even dissolved river inputs, might be the dominant term in the ocean $\mathrm{Nd}$ sources associated with the BE. Determining its behavior and the parameters acting on the BE requires further studies, that are necessary to understand the geographical variations of this process.

Hence, we confirm on regional scale what has been previously suggested on local scale (via field observations) and global scale (via global modeling): Boundary Exchange is an important process in the cycling of $\mathrm{Nd}$ in the ocean.

Acknowledgements. The publication of this article is supported by CNRS-INSU. We would like to thank Mark Siddall and an anonymous reviewer for their helpful comments on the manuscript.

Edited by: M. Hecht

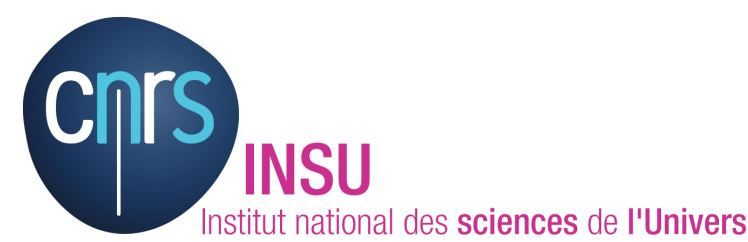

The publication of this article is financed by CNRS-INSU.

\section{References}

Albarede, F., Goldstein, S. L., and Dautel, D.: The neodymium isotopic composition in $\mathrm{Mn}$ nodules from the Southern and Indian Oceans, the global oceanic neodymium budget and their bearing on deep ocean circulation, Geochim. Cosmochim. Acta, 61(6), 1277-1291, 1997.

Arsouze, T., Dutay, J.-C., Lacan, F., and Jeandel, C.: Modeling the neodymium isotopic composition with a global ocean circulation model, Chem. Geol., 239, 165-177, 2007.

Arsouze, T., Dutay, J.-C., Lacan, F., and Jeandel, C.: Reconstructing the Nd oceanic cycle using a coupled dynamical - biogeochemical model, Biogeosciences, 6, 2829-2846, doi:10.5194/bg6-2829-2009, 2009.

Amiotte Suchet, P., Probst, J.-L., and Ludwig, W.: Worldwide distribution of continental rock lithology: Implications for the atmospheric/soil $\mathrm{CO}_{2}$ uptake by continental weathering and alkalinity river transport to the oceans, Global Biogeochem. Cy., 17, 1038, doi:10.1029/2002GB001891, 2003.

Barnier, B., Madec, G., Penduff, T., Molines, J.-M., Treguier, A.M., Le Sommer, J., Beckmann, A., Biastoch, A., Boening, C., Dengg, J., Derval, C., Durand, E., Gulev, S., Remy, E., Talandier, C., Theetten, S., Maltrud, M., McClean, J., and De Cuevas, B.: Impact of partial steps and momentum advection schemes in a global ocean circulation model at eddy-permitting resolution, Ocean Dynam., 56, 543-567, 2006.

Dahlqvist, R., Andersson, P. S., and Ingri, J.: The concentration and isotopic composition of diffusible $\mathrm{Nd}$ in fresh and marine waters, Earth Planet. Sc. Lett., 233, 9-16, 2005.

Dessert, C., Dupré, B., Gaillardet, J., François, L. M., and Allègre, C. J.: Basalt weathering laws and the impact of basalt weathering on the global carbon cycle, Chem. Geol., 202(3-4), 257-273, 2003. 
Drakkar group.: Definition of the interannual experiment ORCA025-G70, 1958-2004, LEGI report, LEGI-DRA-2-112006, update, 2007.

Dutay, J.-C., Jean-Baptiste, P., Campin, J.-M., Ishida, A., MaierReimer, E., Matear, R. J., Mouchet, A., Totterdell, I. J., Yamanaka, Y., Rodgers, K., Madec, G., and Orr, J. C.: Evaluation of OCMIP-2 ocean models' deep circulation with mantle helium ${ }^{-3}$, J. Mar. Syst., 48(1-4), 15-36, 2004.

Ethé, C., Aumont, O., Foujols, M.-A., and Lévy, M.: NEMO reference manual, tracer component : NEMO-TOP, Preliminary version, Note du Pole de modélisation, Institut Pierre-Simon Laplace (IPSL), France, No 28 ISSN No 1288-1619, 2006.

Grousset, F. E., Biscaye, P. E., Zindler, A., Prospero, J., and Chester, R.: Neodymium isotopes as tracers in marine sediments and aerosols: North Atlantic, Earth Planet. Sc. Lett., 87, 367-378, 1988.

Holloway, G.: Observing global ocean topostrophy, J. Geophys. Res., 113, C07054, doi:10.1029/2007JC004635, 2008.

Jacobsen, S. and Wasserburg, G.: Sm-Nd isotopic evolution of chondrites, Earth Planet. Sc. Lett., 50, 139-155, 1980.

Jeandel, C.: Concentration and isotopic composition of $\mathrm{Nd}$ in the South Atlantic Ocean, Earth Planet. Sc. Lett., 117, 581-591, 1993.

Jeandel, C., Arsouze, T., Lacan, F., Techine, P., and Dutay, J. C.: Isotopic $\mathrm{Nd}$ compositions and concentrations of the lithogenic inputs into the ocean: A compilation, with an emphasis on the margins, Chem. Geol., 239, 156-164, 2007.

Jeandel, C., Peucker-Ehrenbrink, B., Godderis, Y., Lacan, F., and Arsouze, T.: Impact of ocean margin processes on dissolved $\mathrm{Si}$, $\mathrm{Ca}$ and $\mathrm{Mg}$ inputs to the ocean, submitted to Nat.Geosci, 2010.

Jones, K., Khatiwala, S., Goldstein, S. L., Hemming, S. R., and Van de Flierdt, T.: Modeling the distribution of Nd isotopes in the oceans using an offline Ocean General Circulation Model, Earth Planet. Sc. Lett., 202(3-4), 610-619, 2008.

Lacan, F.: Nordic Sea and Subarctic Atlantic Water Masses Traced by neodymium Isotopes (Masses d'eau des Mers Nordiques et de l'Atlantique Subarctique tracées par les isotopes du néodyme) Ph.D. Toulouse III University, France, 2002.

Lacan, F. and Jeandel, C.: Denmark Strait water circulation traced by heterogeneity in neodymium isotopic compositions, Deep Sea Res. Pt. I, 51, 71-82, 2004a.

Lacan, F. and Jeandel, C.: Neodymium isotopic composition and rare earth element concentrations in the deep and intermediate Nordic Seas: constraints on the Iceland Scotland Overflow Water signature, Geochem. Geophy. Geosy., 5, Q11006, doi:10.1029/2004GC000742, 2004b.

Lacan, F. and Jeandel, C.: Subpolar Mode Water formation traced by neodymium isotopic composition, Geophys. Res. Lett., 31(14), L14306, doi:10.1029/2004GL019747, 2004c.

Lacan, F. and Jeandel, C.: Neodymium isotopes as a new tool for quantifying exchange fluxes at the continent - ocean interface, Earth Planet. Sc. Lett., 232, 245-257, 2005a.

Lacan, F. and Jeandel, C.: Acquisition of the neodymium isotopic composition of the North Atlantic Deep Water, Geochem. Geophy. Geosy., 6, doi:10.1029/2005GC000956, 2005 b.
Levitus, S., Boyer, T. P., Conkright, M. E., O’Brien, T., Antonov, J., Stephens, C., Stathoplos, L., Johnson, D., and Gelfeld, R.: World Ocean Database 1998, vol. 1, Introduction, NOAA Atlas NESDIS 18, US Government Printing Office, Washington, DC, 1998.

Le Sommer, J., Penduff, T., Theetten, S., Madec, G., and Barnier, B.: How momentum advection schemes influence currenttopography interactions at eddy permitting resolution, Ocean Model., 29, 1-14, 2009.

Michard, A., Albarede, F., Michard, G., Minster, J. F., and Charlou, J. L.: Rare-earth elements and uranium in high-temperature solutions from east pacific rise hydrothermal vent field (13-degreesN), Nature, 303(5920), 795-797, 1983.

Moore, J. K. and Braucher, O.: Sedimentary and mineral dust sources of dissolved iron to the world ocean, Biogeosciences, 5, 631-656, doi:10.5194/bg-5-631-2008, 2008.

Penduff, T., Le Sommer, J., Barnier, B., Treguier, A. M., Molines, J. M., and Madec, G.: Influence of numerical schemes on currenttopography interactions in 1/4 degrees global ocean simulations, Ocean Sci., 3, 509-524, 2007, http://www.ocean-sci.net/3/509/2007/.

Piepgras, D. J. and Wasserburg, G. J.: Neodymium isotopic variations in seawater, Earth Planet. Sc. Lett., 50, 128-138, 1980.

Piepgras, D. J. and Wasserburg, G. J.: Influence of the Mediterranean outflow on the isotopic composition of neodymium in waters of the North Atlantic, J. Geophys. Res., 88, 5997-6006, 1983.

Piepgras, D. J. and Wasserburg, G. J.: Rare earth element transport in the western North Atlantic inferred from isotopic observations, Geochim. Cosmochim. Acta, 51, 1257-1271, 1987.

Rickli, J., Frank, M., and Halliday, A. N.: The hafnium-neodymium isotope composition of Atlantic seawater, Earth Planet. Sc. Lett., 280, 118-127, 2009.

Siddall, M., Khatiwala, S., Van de Flierdt, T., Jones, K., Goldstein, S. L., Hemming, S. R., and Anderson, R. F.: Towards explaining the Nd paradox using reversible scavenging and the Transport Matrix Method, Earth Planet. Sc. Lett., 274, 448-461, 2008.

Stordal, M. C. and Wasserburg, G. J.: Neodymium isotopic study of Baffin Bay water: sources of REE from very old terranes, Earth Planet. Sc. Lett., 77, 259-272, 1986.

Tachikawa, K., Jeandel, C., and Roy-Barman, M.: A new approach to $\mathrm{Nd}$ residence time in the ocean: the role of atmospheric inputs, Earth Planet. Sc. Lett., 170, 433-446, 1999.

Tachikawa, K., Athias, V., and Jeandel, C.: Neodymium budget in the ocean and paleoceanographic implications, J. Geophys. Res., 108, 3254, doi:3210.1029/1999JC000285, 2003.

van De Flierdt, T., Frank, M., Lee, D. C., Halliday, A. N., Reynolds, B. C., and Hein, J. R.: New constraints on the sources and behavior of neodymium and hafnium in seawater from Pacific Ocean ferromanganese crusts, Geochim. Cosmochim. Acta, 68, 38273843, 2004.

Willebrand, J., Barnier, B., Boning, C., Dieterich, C., Hermann, P., Killworth, P. D., Le Provost, C., Jia, Y., Molines, J. M., and New, A. L.: Circulation characteristics in three eddy-permitting models of the North Atlantic, Prog. Oceanogr., 48, 123-161, 2001.

Zhang, Y., Lacan, F., and Jeandel, C.: Dissolved rare earth elements tracing lithogenic inputs over the Kerguelen Plateau (Southern Ocean), Deep-Sea Res. Pt. II, 55, 638-652, 2008. 